\title{
KAJIAN EKOFEMINISME DALAM ESTETIKA SASTRA GOET PAKI ATA KARYA YOSEPH NGADUT
}

\author{
Karolus Budiman Jama \\ Program Studi Pendidikan Bahasa dan Sastra Indonesia, \\ Fakultas Keguruan \& Ilmu Pendidikan, Undana \\ Karolus1007@yahoo.com
}

\begin{abstract}
ABSTRAK
Sastra merupakan salah satu seni yang merupakan unsur kebudayaan. Estetika sastra berkontribusi positif dalam mengendalikan dan mengisi ruang kosong kehidupan manusia. Seperti estetika sastra umumnya, estetika sastra goet etnik Manggarai di Flores memiliki posisi yang strategis dalam menanamkan nilai-nilai kehidupan, baik itu nilai moral, sosial, pendidikan, spiritual, dan nilai estetik kepada generasi penerusnya. Artikel ini mengupas tentang kajian ekofeminisme terhadap estetika sastra go'et paki ata karya Yospeh Ngadut. Peneltian ini tergolong dalam penelitian kepustakaan dengn menggunakan penelitian kuasikualitatif. Metode penelitian ini menggunakan metode hermeneutika untuk mendapatkan pemaknaan sastra goet paki Ata yang optimal. Dari hasil analisis data terhadap teks estetika sastra goet paki ata diperoleh temuan berikut ini. Estetika sastra go'et Paki Ata merupakan proses kreatif filosofis yang menemukan jalan kembali untuk menemukan diri yang lain pada alam. Estetika sastra go 'et Paki Ata adalah tafsiran estetik yang kritis terhadap dominasi kuasa patriarki yang mengsubordinasi kaum perempuan dalam melihat alam sebagai dirinya.

Kata kunci: Ekofeminisme, estetika, sastra, go'et.
\end{abstract}

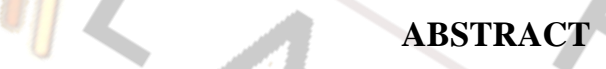

Literature is an art that is an element of culture. Literary aesthetics contribute positively in controlling and filling empty spaces in human life. Like literary aesthetics in general, the Manggarai ethnic goet literary aesthetic in Flores has a strategic position in instilling the values of life, be it moral, social, educational, spiritual, and aesthetic values in future generations. This article examines the study of eco-feminism on the literary aesthetics of Yospeh Ngadut's go'et paki ata. This research is classified as a library research using quasi-qualitative research. This research method uses the hermeneutic method to obtain optimal literary meaning of Goet Paki Ata. From the results of data analysis on the literary aesthetic text of Goet Paki ata, the following findings are obtained. The literary aesthetic of Paki Ata's go'et is a philosophical creative process that finds a way back to find another self in nature. The literary aesthetic of Paki Ata's go'et is an aesthetic interpretation that is critical of the dominance of the patriarchal power that subordinates women to seeing nature as herself.

Keywords: Eco-feminism, aesthetics, literature, go'et

\section{Pendahuluan}

Unsur kebudayaan salah satunya adalah seni. Karya sastra merupakan salah satu bidang karya seni yang mediumnya adalah bahasa. Dalam karya sastra, bahasa memegang peranan penting. Lewat eksploitasi bahasa, estetika sastra dimunculkan sebagai kekuatan dalam menggugah dimensi terdalam emosi manusia (Ratna, 2007:38). Disinilah karya sastra memiliki posisi yang strategis dalam kehidupan manusia. Seperti karya seni lainnya, karya sastra mampu mengontrol dan mengisi keterbatasan dunia. Hadirnya karya sastra tidak sekadar melengkapi ruang-ruang rutin kehidupan manusia. Sastra masuk pada relung jiwa sebagai penghilang dahaga dalam lelah memburu pemenuhan materi. 
Sastra berkekuatan untuk mendobrak ketimpangan kehidupan sosial dan bahkan menjadi alat kampanye perlindungan terhadap lingkungan hidup. Karya sastra seperti karya seni umumnya berfungsi sebagai pengontrol dan pengeritik terhadap realitas dunia. Karya seni hadir untuk mengontrol kecenderungan reifikasi terhadap kebudayaan yang berimplikasi terhadap krisis seni dan kebudayaan secara luas.

Banyak karya sastra yang merefleksikan pentingnya menjaga lingkungan alam. Karya sastra sebagaimana definisi yang diberikan terhadapnya merupakan alat yang indah untuk memberi petunjuk, pengajaran tentang nilai moral kehidupan. Melalui sastra, individu atau kelompok masyarakat tertentu menampilkan pandangan dunia atau ideologi hingga menjadi alat politik (Susanto, 2011: $1 \& 10$ ).

Dalam estetika tradisi, terutama dalam ritual penghormatan terhadap leluhur, estetika sastra dilihat sebagai puncak dari kebudayaan. Hal ini karena masyarakat tradisi melihat tuturan ritual lekat dengan estetika, dan lebih dalam dari itu, tuturan yang estetik itu adalah doa. Masyarakat tradisi sangat menyadari peran estetika sastra dalam kehidupan, selain substansinya juga karena fungsi. Keduanya terinterdependensi. Alasan penting inilah mengapa masyarakat tradisi memproduksi karya sastra. Ratna (2007:39) mengatakan secara fungsional sastra berhubungan dengan karya seni yang lain, berhubungan dengan agama, mitos, filsafat, ilmu pengetahuan, arsitektur, politik, ekonomi, dan sebagainya.

Go'et dalam tradisi etnik Manggarai merupakan satu bagian dari produksi seni masyarakatnya. Go'et adalah sebuah karya estetika sastra yang berperan penting dalam menanamkan nilai-nilai kehidupan. Melalui go'et selain nilai estetika, nilai-nilai lain seperti sosial, moral, religius, pendidikan ditanamkan dan diwariskan secara menggenarasi. Go'et muncul ketika ada percakapan serius dalam ritual adat seperti kelahiran, perkawinan, kematian, penti, wuat wa' $i$, pembangunan rumah adat serta acara adat lainnya. Go'et yang dituturkan disesuaikan dengan tema acara adat. Dalam kehidupan sehari-hari go'et dimunculkan pada peristiwa-peristiwa tertentu seperti menangani masalah relasi sosial seperti mendamaikan orang yang sedang bertikai. Dan dalam pergaulan, go'et diselipkan pada percakapan untuk memberi nasihat dari orang tua kepada yang muda agar hidup menjadi baik nantinya.

Estetika sastra go'et jarang didokumentasikan dalam bentuk buku. Seorang budayawan dan seniman bernama Yoseph Ngadut melalui bukunya berjudul "Toing agu Titong: Belajar Kebijaksanaan Hidup dari Khazanah Go'et Budaya Manggarai”, menampilkan karya-karya go'et-nya. Buku karya estetika sastra go'et ini merupakan 'buku tangan' yang dapat dijadikan sumber data karya ilmiah estetika sastra etnik Manggarai. Karya-karya estetika go'et dalam buku ini dapat dijadikan pegangan dalam memahami nilainilai kehidupan bagi generasi muda etnik Manggarai. Paki Ata merupakan salah satu judul go'et yang tampilkan dalam buku ini. Go'et ini, merefleksikan pentingnya menjaga ekositem dan harmonisasi kehidupan serta kental dengan nilai spiritual.

Dalam tulisan ini yang menjadi fokus analisis penulis adalah go'et Paki Ata. Go'et ini diangkat sebagai fokus kajian ekofeminisme karena go'et ini memiliki karakteristik ekofeminisme dalam estetika sastranya. Estetika sastra go'et karya Yoseph Ngadut ini memanggil kembali kesadaran akan spiritualitas hidup yang bersumber dari ibu bumi. Mengungkap dan mengiformasikan isi estetika sastra go'et Paki Ata dalam penelitian ini merupakan sumbangan penting bagi ilmu pengetahuan dan estetika sastra umumya, dan secara khusus bagi masyarkat etnik Manggarai sebagai kekayaan intelektualnya. Hal inilah yang menjadi landasan dalam melakukan analisis melalui perspektif ekofeminisme. 


\section{Metode Penelitian}

Penelitian ini merupakan jenis penelitian kepustakaan. Penelitian ini menggunakan penelitian kuasi-kualitatif melalui metode hermeneutika. Ratna (2011:44-45) menulis selain sebagai ilmu, hermeneutika merupakan metode yang paling sering digunakan dalam penelitian karya sastra. Metode hermeneutika dianggap tepat untuk memahami karya sastra dan merupakan metode ilmiah yang paling tua sejak zaman Plato dan Aristoteles. Metode ini digunakan dalam penelitian ini karena, estetika sastra go'et Paki Ata yang ditulis oleh Yoseph Ngadut merupakan karya tulis sastra yang harus dicari maknanya yang paling optimal. Data dalam penelitian ini diperoleh dari sastra go'et Paki Ata dalam buku kumpulan go'et yang ditulis oleh Yoseph Ngadut.

Dalam menganalisis data langkah-langkah yang dilakukan sebagai berikut. (1) Estetika sastra go'et Paki Ata dibaca dengan teliti dan menyeluruh sehingga semua kata dipahami. (2) Menetapkan data yang sesuai perspektif ekofeminisme. (3) Memberi kode dengan huruf dan angka (EF: Ekofeminisme) pada teks yang berkaitan dengan ekofeminisme. (4) Menganalisis data sesuai bentuk teks berdasarkan teori ekofeminisme.

\section{Temuan}

Estetika sastra go'et Paki Ata merupakan proses kreatif filosofis yang menemukan jalan kembali untuk menemukan diri yang lain pada alam. Estetika sastra go'et Paki Ata adalah tafsiran estetik yang kritis terhadap dominasi kuasa patriarki yang mensubordinasi kaum perempuan dalam melihat alam sebagai dirinya. Estetika sastra go'et ini menegaskan kembali refleksi terhadap peran ekofeminisme sebagai gerakan gelombang ketiga feminis dalam menjaga kelestarian alam.

\section{Teori}

Maryaeni \& Kumalasari (ed, Endraswara, 2016:35) menyebut bahwa ekofemenisime merupakan satu cabang feminis yang muncul pada gelombang ketiga dalam gerakan feminisme. Ekofeminisme hadir untuk menjelaskan tentang hubungan perempuan dan alam. Dalam pandangan ekofeminisme perempuan memiliki peran penting untuk menjaga kelestarian alam agar tetap nyaman dan asri. Hadirnya teori ekofeminisme memberi isyarat dan mewanti bahwa kerusakan alam dibiangi oleh kuasa industri modern yang mewakili dominasi logika patriarki barat. Ekofeminisme hadir sebagai kritik terhadap sikap manusia terhadap alam. Alam dieksploitasi untuk kepentingan manusia belaka dan alam hanya sebagai instrumen untuk memenuhi kebutuhan hidup manusia. Ekofeminisme melihat perusakan terhadap alam sama dengan merusak kehidupan kaum perempuan yang mewariskan kehidupan. Gagasan penting ekofeminisme adalah terdapat hubungan yang erat dan langsung antar opresi terhadap perempuan dan opresi terhadap alam (Suryaningsih dalam Candaraningrum, (ed), 2013:32, Tong, 2010:359).

\section{Pembahasan}

Berikut ini merupakan estetika sastra go'et Paki Ata karya Yoseph Ngadut, yang ditampilkan dalam tabel.

\begin{tabular}{|c|c|c|}
\hline Teks Utuh Go'et Paki Ata & $\begin{array}{l}\text { Terjemahan (pnj:Yoseph } \\
\text { Ngadut) }\end{array}$ & $\begin{array}{lrr}\text { Kode dan } & \text { Teks yang } \\
\text { mengandung } & & \text { unsur } \\
\text { ekofeminisme } & & \\
\end{array}$ \\
\hline $\begin{array}{l}\text { Paki haju kanggang } \\
\text { Pape te haju api laing } \\
\text { Paki haju ta'a } \\
\text { Re'ing lata tu'a }\end{array}$ & $\begin{array}{l}\text { Potong kayu kering } \\
\text { Dipakai buat kayu bakar } \\
\text { Potong kayu mentah } \\
\text { Dilarang oleh orang tua }\end{array}$ & $\begin{aligned} &> \text { EF1: Paki haju } \\
& \text { Kanggang (Potong } \\
& \text { kayu kering) } \\
&>\text { EF2: Pape te haju }\end{aligned}$ \\
\hline
\end{tabular}




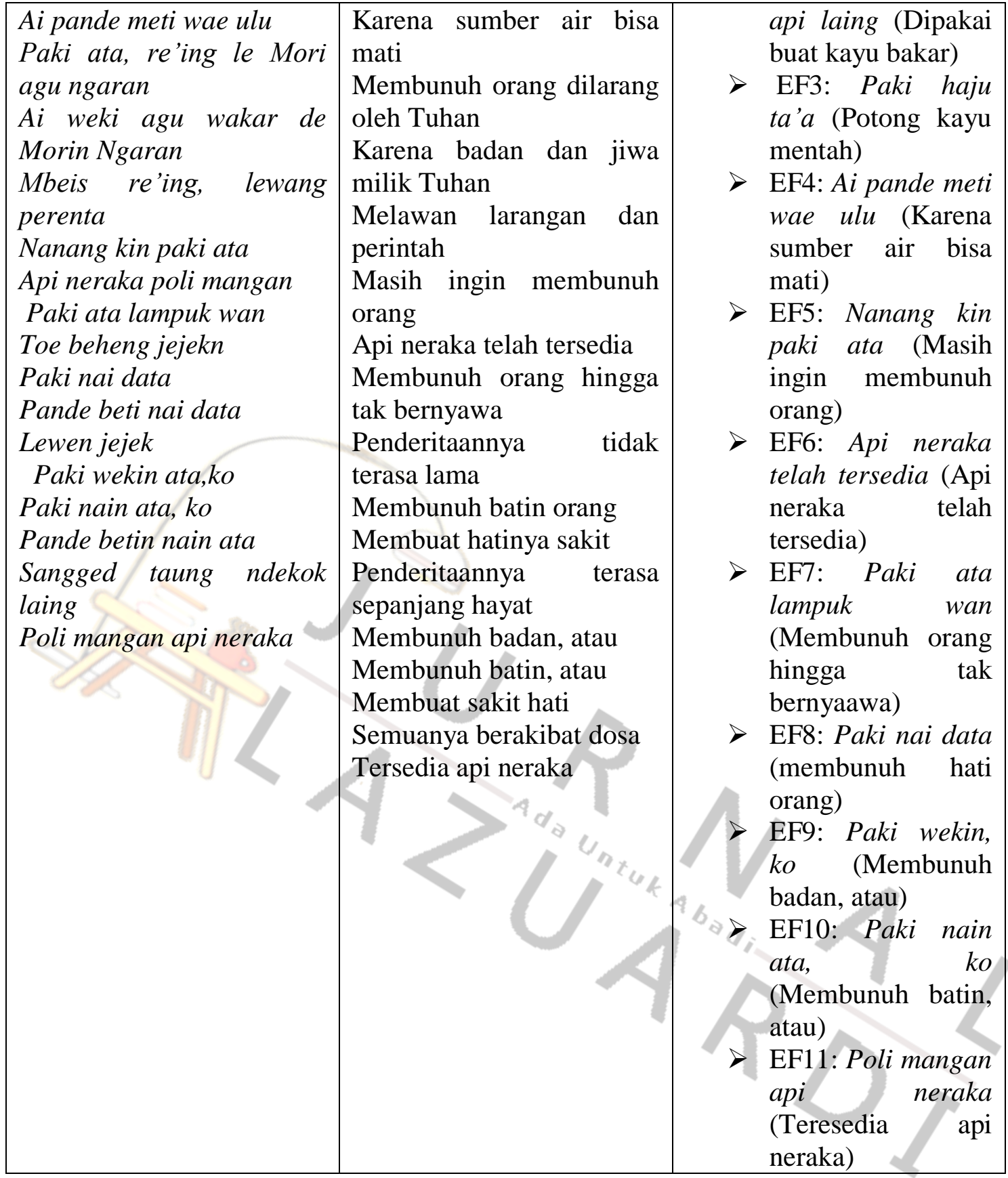

\section{(Sumber: Buku “Toing Agu Titong": Belajar Kebijaksanaan Hidup Dari Khazanah Go'et Budaya Manggarai. Penulis Yoseph Ngadut, 2016: 10).}

Dari data yang terkumpul di atas, terdapat sebelas teks go'et Paki Ata karya Yoseph Ngadut yang teridentifikasi sebagai unsur ekofeminisme. Kata paki dalam terjemahan kamus bahasa Manggarai yang ditulis oleh Verheijen menunjuk pada beberapa arti yaitu, sembelih, memotong, memukul, tebang, bunuh. Kata ata dalam kamus yang sama diartikan orang, manusia. Merujuk pada pengertian dua kata ini, paki ata dapat diartikan sebagai membunuh orang. Orang yang dimaksud dalam estetika sastra go'et yang ditulis oleh Yoesph Ngadut, merujuk pada pandangan teori ekofeminisme adalah perempuan yang merepresentasikan 
tentang alam. Paki yang berarti membunuh, memotong, sembelih, memukul, tebang dalam perspektif ekofeminisme bermakna kekuasaan yang sifatnya di atas dan hirarkis.

Dua kata yang menjadi judul estetika sastra go'et Paki Ata menunjukkan kuasa yang bernilai hirarkis, pola pikir atas bawah, bahwa yang diatas selalu mendominasi yang dibawah. Laki-laki mendominasi perempuan, kuasa pengetahuan modern menjadi eksklusif dan menekan pengetahuan yang tersubordinasi (Tong, 2010: 359-360). Pola hirarki, dominasi, eksklusifisme, kuasa inilah yang menjadi poin penting sebagai antitesa kaum ekofeminisme. Tong, selanjutnya menjelaskan yang menjadi akar ekofeminisme adalah menentang kerusakan terhadap alam yang dilakukan oleh laki-laki. Kemudian berlanjut kepada kritik terhadap filsafat Rene Descartes yaitu filsafat yang mengutamakan pikiran atau nalar yang berpusat pada manusia untuk menguasai materi atau benda yang tidak mampu berpikir. Implikasi dari konsep filsafat ini adalah hadirnya pemikiran dan ilmu pengetahuan modern yang bebas untuk menguasai alam. Persis inilah yang menjadi tema besar estetika sastra go'et Paki Ata. Dari sini pemaknaan judul estetika sastra go'et Paki Ata adalah membunuh alam akibat kuasa dominasi pengetahuan modern yang mewakili kaum patriarki.

Selain terepresentasi pada judul goet, karakteristik ekofeminisme kemudian dipertegas pada bait-bait go'et. Bait pertama (EF. 1,2,3,4) dalam estetika sastra go'et ini, terdapat empat baris go'et ekofeminisme yaitu, kayu kering (haju kanggang), kayu api (haju api), kayu mentah (haju ta'a), sumber air (wae ulu). Kayu yang mewakili tumbuhan, dan air merupakan salah satu dari berbagai unsur yang menjadi fokus perhatian ekofeminisme. Hal ini sealur dengan apa yang disampaikan oleh Leopold (Tong, 2010:363) pentingnya memikirkan alam sebagai "mata air energi yang mengalir melalui siklus tanah, tumbuhan, dan binatang". Pandangan Leopold didasari oleh pengamatannya bahwa bumi adalah suatu sistem kehidupan yang terkait satu dengan yang lain, jika salah satu diantaranya mengalami sakit atau kerusakan harus diobati. Bait-bait selanjutnya dalam fitur (EF. 5,6,7,8,9,10,dan 11) langsung menunjuk pada orang yaitu perempuan sebagai tokoh utama dalam estetika sastra go'et ini.

Setiap bait dalam estestika sastra go'et paki ata ini menampilkan kausalitas atau hubungan sebab akibat. Pada fitur EF.1,2 memberi ruang yang bebas untuk memanfaatkan potensi alam secara bijak. Bahwa hanya kayu keringlah yang dapat dimanfaatkan untuk dijadikan kayu bakar. Memotong atau mengambil pohon kering dibaca sebagai tindakan yang bijak. Dalam pemaknaan yang lebih luas, memotong kayu kering berarti mengambil sesuatu yang telah matang untuk dimanfaatkan. Ini merupakan sebuah upaya pemanfaatan kekayaan demi kesejahteraan. Pandangan ini sealur dengan pandangan Naess dan Sessioons dalam mengartikulasikan delapan prinsip "ekologi-dalam" yang salah satu pointnya adalah manusia tidak berhak untuk mereduksi kekayaan dan keragaman, kecuali untuk memenuhi kebutuhan vital. Pandangan ini kemudian dipertegas lagi oleh Peter Wentz bahwa mengambil sesuatu dari alam dengan alasan yang memadai tidak menjadi masalah terkait kepentingan moral (Tong, 2010:365-366). Estetika sastra go'et Paki Ata diawali oleh fitur EF.1,2 ini adalah sebuah penegasan bahwa hal utama adalah kemampuan pikiran manusia tidak boleh melampaui yang moral. Manusia sebagai mahluk berpikir harus mampu menempatkan pikirannya untuk memanfaatkan alam dengan baik. Fitur EF.1,2 adalah sebuah ajaran kebijaksanaan tentang pentingnya membangun relasi dengan alam. Manusia menjaga alam dan memelihara lingkungan seperti pohon untuk ketersediaan air adalah suatu kebutuhan.

Hubungan kausalitas semakin dipertegas dalam fitur EF.3,4. Fitur ini jelas menunjukkan larangan untuk menebang pohon yang hidup karena akan menyebabkan kekurangan air. Sutrisno (2006: 6-7) dalam esainya tentang air menulis. Tumbuhan seperti 
bambu hijau, pepohonan perdu dan bunga liar yang asli hidup karena air. Dia memandang air harus dihormati karena rohnya menghidupi. Perusakan terhadap alam sama posisinya perlakuan terhadap sesama yang tidak menghormati harkatnya. Pandangan Sutrisno ini jelas menampakkan kausalitas bahwa air menghidupi karena ada pohon yang menghasilkan air. Masyarakat etnik Manggarai di Flores, melakukan ritual barong wae untuk menghormati roh penjaga air. Ritual ini dilakukan sebagai dialegtika antar menjaga air dan memelihara pohon yang ada disekitar sumber air. Hal inilah yang disampaikan oleh Candraningrum (2017:7) bahwa terdapat hubungan yang fundamental tentang alam dan manusia. Manusia mampu berdialog dengan alam ketika manusia menaruh dirinya kepada alam. Manusia harus membangun relasi yang setara dengan alam. Disana ada nada harmonis ketika manusia melakukan percakapan yang intens dan akrab dengan tidak sewenang-wenang terhadap alam.

Dalam perspektif estetik, menebang pohon sama dengan memusnahkan kecantikan pada perempuan. Kecantikan yang dimaksud bukan hanya tentang keindahan tubuh dan wajah. Akan tetapi kecantikan dalam (iner beauty) yaitu keindahan roh yang membuahi, mengandung, melahirkan, menghidupi, membesarkan dari cara menyusui lewat air kehidupan. Ada dua makna kecantikan yang ditangkap. Pertama, kecantikan tubuh/luar. Alam yang dirusak akan kehilangan harmonisasinya, kehilangan posturnya yang terbentuk dari proses alamiah yang Panjang. Membunuh salah satu bagian tubuh alam berarti menghilangkan keutuhan kecantikan. Ini yang disebut oleh Plato keindahan terdapat dalam kesederhanaan. Artinya keindahan itu tidak dapat dipisahkan lagi atau disederhanakan. Kedua, kecantikan dalam/roh. Merusak alam sama dengan melepas roh dari tubuhnya. Ketika roh dilepas maka kehilangan aura estetiknya. Ini berarti sama dengan menghilangkan kehidupan itu sendiri (EF.5,7,8).

Pandangan ekofeminisme menegaskan, membunuh adalah perbuatan yang bertentangan dengan moral. Moral merupakan potensi pembentuk diri sebagai mahluk berkesadaran yang di dalamnya bertugas untuk menjaga integritas, stabilitas, dan kecantikan (Tong, 2010:365). Gilligan seperti yang disampaikan oleh Rachels (2004:292) dan juga dikutip oleh Danardono (ed. Candraningrum, 2013:52) tentang etika kepedulian. Bahwa orientasi dasar dari moral perempuan adalah kepedulian mereka terhadap yang lain, bukan saja soal kemanusiaan umumnya dan bukan semata tentang pemenuhan kebutuhan tetapi terutama manusia bergantung dengan yang lain.

Dua pandangan yang dikemukakan oleh Tong dan Gillian di atas dimengerti sebagai antitesa dari persoalan, bahwa demi hidup manusia lantas mengorbankan yang lain. "Yang lain" disini tidak saja dimaksudkan pada manusia sebagai indvidu di luar diri, tetapi juga lingkungan alam yang merupakan representasi atau bagian dari diri perempuan itu sendiri. Tidak heran mengapa perempuan berfokus dan memiliki sikap kepedulian yang intim terhadap persoalan alam. Hal ini karena mereka memiliki etika kepedulian terhadap alam menjadi penting. Sehingga perbuatan yang menghilangkan bagian dari diri mereka, sama dengan mengambil esensi lain dari hidup mereka.

Estetika sastra go'et Paki Ata adalah proses kreatif dan filosofis dalam mencari jalan untuk menemukan diri yang lain dari konsep berpikir patriarki. Hal ini ditegaskan oleh Salleh (Tong, 2010:367) sebagai kritik terhadap konsep "Ekologi- Dalam”. Ia mengatakan "Gerakan ekologi-dalam tidak pernah benar-benar terjadi, hingga laki-laki cukup berani untuk menemukan kembali dan mencintai bagian dirinya yang perempuan". Pendapat ini disepakati oleh kaum ekofeminisme, bahwa kebencian terhadap perempuan sama dengan kebencian terhadap alam. Dari perspektif ini, estetika sastra go'et Paki Ata hendak menegaskan kembali kecintaan terhadap alam adalah jalan pulang untuk bertemu dengan diri sendiri atau bagian 
yang lain dari diri sendiri. Pemaknaan atas ini dapat dikaitkan dengan estetika pertunjukan Caci etnik Manggarai di Flores yang merepresentasikan perlindungan terhadap alam dan pemujaan terhadap ibu bumi yang menghidupi (Jama, Disertasi 2020).

Berefleksi lebih dalam akan peran perempuan yang termanifestasi pada estetika sastra go'et Paki Ata. Perempuan sulit dilepas dari kedekatannya dengan alam, hal ini karena secara kultur hampir seluruh etnis meyakini bahwa perempuan menyatu bersama alam. Ada tiga alasan yang meyakini pandangan ini seperti yang dikatakan oleh Ortner. (1) Fisiologi perempuan. Perempuan memiliki kemampuan merawat kehidupan dalam waktu relatif yang lama. (2) Dalam konteks domestik perempuan menempati posisi vital karena disana ada transformasi kultural dan produk kebutuhan pokok. (3) Psikologi perempuan dibentuk atas dasar fungsi ibu melalui sosialisasi diri yang cenderung pada cara berpikir relasional, konkret, dan khusus dibanding dengan cara berpikir laki-laki (Tong, 2010:371). Evania menulis, bahwa dalam melakukan tugasnya perempuan menggunakan berbagai bagian otaknya. Dalam berpikir, perempuan melibatkan seluruh otaknya. Otak perempuan lebih terintegrasi dengan hubungan yang lebih kompleks antar dua belahan otak, pikiran dan emosi, berpikir secara logis dan emosional (2011:54). Bertumpu pada pandangan ini, secara logis dapat dipahami bahwa memang perempuan sangat dekat dengan alam dan lebih banyak memahami tentang alam. Dan mereka tidak salah, bahkan perlu afirmasi dari berbagai komponen ketika mendeklarasikan diri mereka adalah alam itu sendiri.

Estetika sastra go'et Paki Ata dalam fitur EF.7,8,9,10,11 adalah kritik yang tajam terhadap eksploitasi alam untuk mencari keuntungan. Keuntungan dari eksploitasi terhadap alam hanyalah ilusi dan mitos karena hanya memberi kesadaran yang semu. Pada fitur EF.11 jelas ditegaskan implikasinya adalah menuai keburukan bagi masa kini dan masa yang akan datang. Masa kini, bumi mengalami pemanasan global (global warming), dan masa yang akan datang generasi tidak menikmati lagi keragaman hayati akibat bencana alam sabagai dampak dari menebang hutan secara masif. Dalam kondisi inilah manusia sedang terjebak pada permainan drama kesadaran yang semu. Atau dalam Bahasa Piliang (2019:247) disebut sebagai industrialisasi kesadaran. Industrialisasi kesadaran muncul akibat industri budaya yang bukan mengentaskan atau mencerdaskan akan tetapi hanya akan mengeksploitasi.

Eksploitasi dekat dengan konsep kesenangan kaum hedonis. Atas pertanyaan Sokrates tentang tujuan akhir dari kehidupan manusia, Aristippos menjawab yang sungguh baik bagi manusia adalah kesenangan. Ia juga mengatakan kesenangan itu bersifat badani karena hakikatnya tidak lain dari gerak dalam badan (Bertens, 2011:250). Apabila menebang pohon karena menyebabkan terganggunya kesenangan, maka tindakan ini adalah sebuah perilaku hedonis. Perilaku hedonis merupakan pola antroposentris, dalam pola ini manusia selalu menjadi pusat, dan sepertinya mengabaikan yang lain termasuk alam didalamnya. Konsekuensi lain dari sikap hedonis ini adalah dapat melukai yang lain atau mencelakai untuk sebuah kesenangan. Alam dilukai, pohon ditebang hanya karena untuk kesenangan. Ekofeminisme hadir di sini untuk mengoreksi pandangan hedonis bahwa kewajiban untuk sebuah kesenangan dalam prinsip yang mengabaikan persamaan keadilan terhadap alam adalah sesuatu yang salah.

Eksploitasi terhadap alam dengan menebang hutan dimaknai sebagai bentuk lain dari komoditas terhadap perempuan. Perempuan hanya dilihat sebagai objek nilai, yang menurut Marx nilai terdiri dari nilai guna (use value) dan nilai tukar (exchange value). Use value yaitu nilai untuk memenuhi kebutuhan tertentu. Exchange value yaitu nilai untuk diperjualbelikan (Suseno, 2016:188-189). Perempuan dalam nilai guna hanya untuk sebuah kebutuhan seks tanpa dasar cinta umpamanya. Kebutuhan ini ibarat menebang hutan karena nafsu/birahi 
kapitalisme, yang tidak memiliki kesadaran cinta terhadap kehidupan di dalamnya. Setelah digunakan untuk memenuhi kebutuhan kaum kapitalis hidung belang, kemudian ia ditinggalkan. Perempuan dalam nilai tukar karena memiliki kelebihan untuk diperjualbelikan. Perempuan dalam representasi alam atau sebaliknya, dilirik hanya karena ada nilai tukar yang melekat pada dirinya. Saat kehilangan nilai tukar, ia dicampakkan sebagai mahluk yang berdosa karena membawa masalah bagi kehidupan. Saat terjadi bencana alam, bukan manusia yang disalahkan tetapi alamlah yang diomeli. Alam dianggap tidak bersahabat ketika hilang kesuburannya dan tidak lagi memberi kehidupan pada tanaman. Alam dan perempuan selalu menjadi objek kesalahan ditengah keserakahan kaum kapitalis yang mengawini pengetahuan modern. Implikasi dari kongsi kaum kapitalis dan pengetahuan modern, hutan sebagai rumah satwa dirambah karena ada potensi dalam nilai tukar. Misalnya, hutan ditebang kemudian diganti dengan perkebunan kelapa sawit atau untuk industri tambang.

Perempuan dalam industri senipun tidak luput dari tekanan kelompok kapitalis. Banyak pekerja seni yang terperangkap dalam godaan kebutuhan pasar. Penari atau penyanyi dangdut bukan mengekspresikan seni atau mengeksplorasi seni gerak atau suaranya tetapi mengeksploitasi tubuhnya. Eksploitasi terhadap hutan sama halnya dengan eksploitasi tubuh perempuan dalam undustri seni yang disebut oleh W.F. Haung (dalam Piliang, 2019:251) sebagai estetika komoditas karena hanya untuk sebuah keuntungan. Industri seni ini barangkali tidak dapat dikategorikan sebagai estetika (baca: penulis) karena bentuknya diciptakan untuk sebuah daya tarik, keterpesonaan yang fetishism sebagai hasrat yang rendah terutama sensualitas. Industri seni yang mengkomersilkan tubuh perempuan sangat berbeda dengan seni tradisi untuk sebuah kesuburan seperti seni pertunjukan Lengger. Dalam seni pertunjukan ini, ritual kesuburan dilakukan oleh para penari sebagai petanda keseimbangan alam yang mampu memberi kehidupan kepada tumbuhan yang dipercayai mempunyai nyawa (Indriyani dalam Candraningrum\& Hunga (ed), 2015:165). Pada tataran ini, seni tradisi dan pelakunya adalah bagian dari alam. Alam kemudian memberi kesuburan pagi tanaman yang selanjutnya dinikamti oleh manusia. Hal menarik dari masyarakat tradisi adalah mereka tidak lupa untuk kembali bersyukur dan mempersembahkan hasil bumi pada alam sebagai manifestasi sang pencipta/sang semesta.

\section{Penutup}

Setiap karya seni tradisi memberi nilai bagi masyarakatnya. Karya seni berfungsi mengontrol tata kelola kehidupan, baik itu budaya, sosial dan alam. Estetika sastra go 'et Paki Ata karya Yoseph Ngadut oleh penulis dibaca sebagai representasi ekofeminisme yang merupakan pergerakan gelombang ketiga feminisme. Estetika sastra go'et Paki Ata memberi penegasan bahwa penting menjaga alam sebagaimana kesetaraan keadilan terhadap manusia. Kesetaraan keadilan ini muncul oleh kepedulian perempuan terhadap alam, dan alam merupakan bagian dari wilayah hidup perempuan. Estetika sastra go'et Paki Ata memanggil kembali kesadaran akan kepedulian terhadap alam bukan karena memberi kehidupan dan manfaat bagi manusia. Akan tetapi karena ada kesetaraan dan alam adalah bagian dari hidup perempuan yang perlu dijaga untuk keberlanjutan serta eksistensi inherennya. 


\section{DAFTAR PUSTAKA}

Bertens. K. 2011. Etika. Jakarta: Kompas Gramedia.

Candraningrum, Dewi. 2013. Ekofeminisme: Dalam Tafsir Agama, Pendidikan, Ekonomi, dan Budaya. Yogyakarta: Jalasutra.

Candraningrum, Dewi. 2017. (ed) Ekofeminisme II: Narasi iman, Mitos, Air \& Tanah. Jogjakarta: Jalasutra.

Candraningrum, Dewi \& Hunga, Restiani. I.A. 2015. Ekofeminisme III: Tambang, Perubahan Iklim \& Memori Rahim. Yogyakarta: Jalasutra.

Evina, Putri. 2011. Menguak Rahasia Otak Perempuan: Menyingkap dan Memahami Kemukjizatan-Kemukjizatannya. Yogyakarta: Sinar Kejora.

Jama, Budiman, Karolus. 2020. Disertasi "Dekonstruksi Ruang Simbolik Atas Matinya Estetika Caci Etnik Manggarai Di Flores". Udayana

Ngadut, Yoseph. 2016. Toing agu Titong: Belajar Kebijaksanaan Hidup dari Khazanah Go'et Budaya Manggarai. Ruteng: Sanggar Lawe Lenggong.

Piliang, Yasraf. 2019. Medan Kreativitas: Memahami Dunia Gagasan. Yogyakarta: Cantrik Pustaka.

Ratna, Kutha, Nyoman. 2011. Antropologi Sastra: Peranan Unsur-unsur Kebudayaan dalam Proses Kreatif. Yogyakarta: Pustaka Pelajar.

Suseno, Magnis, Franz. 2016. Pemikiran Karl Marx: Dari Sosialisme Utopis ke Perselisihan Revisionisme. Jakarta: Kompas Gramedia.

Sutrisno, Mudji. 2006. Oase Estetis: Estetika dalam kata dan sketza. Jogjakarta: Kanisius.

Susanto, Dwi. 2012. Pengantar Teori Sastra. Jakarta: Caps.

Tong, Putnam, Rosemare. 2010. Feminist Thought: Pengantar Paling Komprehensif kepada Arus Utama Pemikiran Feminis. Yogyakarta: Jalasutra.

Veheijen. J.A. Jilis. 1970. Kamus Bahasa Manggarai. 'S-Gravenhage: Koninklijk Instituut Voortaal-Land en Volkenkunde. 